\title{
In Vitro Evaluation of Antiviral / Virucidal Activity of Naja Nubiae (Elapidae) Venom Against Rift Valley Fever and Herpes Simplex Virus Type -1 (HSV-1) Using Cell Culture
}

\author{
Kareem A. Yonys*, Samy A. Saber, Abir A. El-Fiky, Aly F. Mohamed
}

Department of ${ }^{1}$ Zoology, Faculty of Science (Boys branch), Al-Azhar University; ${ }^{2}$ ANDI COE in Antivenom Research and ${ }^{3}$ R\&D Sector VACSERA

*Corresponding author: Kareem Ahmed, Mobile: (+20) 01158643103, Email: karemyonys1990@ gmail.com

\begin{abstract}
Background: Venoms are pretentious products secreted by snake, invertebrates and scorpions. Venoms composed of different proteins, toxic fractions, enzymes and hormones. Some fractions proved bioactivity including anticoagulation. antimicrobial and anticancer activity.

Objective: The aim of the current study was to in vitro evaluate the Antiviral / virucidal activity of Naja nubia (Elapidae) venom against Rift Valley Fever (RVFv) and Herpes simplex virus type -1 (HSV-1) using cell culture.

Materials and methods: Toxicity of tested venom was performed using cell culture to determine the safe concentration using MTT assay. Antiviral activity was conducted by precultured cell treatment with safe concentration of snake venom for $24 \mathrm{hr}$. then virus was dispensed as $0.1 \mathrm{ml} /$ well in quadrate for each dilution. TCID50s of snake venom safe concentration treated and untreated cells were determined. The difference is the antiviral activity. Virucidal was conducted by mixing one part of virus models with nine parts of the safe concentration of snake venom at $37^{\circ} \mathrm{C}$. The infectivity titer / time interval was determined according to Reed and Menuch equation.

Result: Data record revealed that the cell viability was concentration dependent recording an IC50 of $9.3 \mu \mathrm{g} / \mathrm{ml}$. Also, venom showed a very limited antiviral activity but the virucidal activity was time dependent and showed a depletion rate in the order of $0.72 \log (10)$ and $0.94 \log (10) / \mathrm{hr}$. for RVFV and HSV-1 respectively indicating that RVFv was moderately sensitive than HSV-1.

Conclusion: It could be concluded that Naja Nubiae venom is a potentially virucidal agent than antiviral one with persistent inactivation potential.
\end{abstract}

Keywords: Naja nubiae, Antiviral, Virucidal, Rift valley forever virus, Herpes simplex type 1, cell culture, MTT.

\section{INTRODUCTION}

Viruses are capable of rapidly mutating and infecting host cells, sometimes aided by virus-coded peptides that counteract immune defense of host cells. Although a large amount of compounds for inhibiting multiple viral infections and disease progression have been recognized, the discovery of more efficient agents is urgent. Furthermore, Very few viral vaccines are accessible, and not all are effective, in proportion to the wide variety of viral diseases. Thus, new antiviral substances extracted from natural products, including those extracted from venom animals, have been prospected $^{(\mathbf{1})}$.

Venoms are complicated mixtures of hundreds of molecules, mostly peptides that present a wide range of biological activities and have developed to target the biochemical machinery of various pathogens or host cellular structures. In addition, non-venomous compounds have antiviral activity. Peptides described from animal venoms presenting antiviral activity, strengthening them as significant instruments to develop new virucidal agents. Rift Fever Virus (RVF), Dengue viruses are members of the Bunyaviridae family and the genus phlebovirus; has been separated from sheep and animals in Kenya. By 1944, and was separated from the Semliki Forest in Uganda. In 19501 a large outbreak occurred in South Africa. It reached
Egypt in 1979-1980, with an infection of 200,000 or more individuals and 600 fatalities. In addition, in 1979, the disease moved to Madagascar. RVF emerged in Saudi Arabia and Yemen in the 21st century and reported 200 deaths. It came to Sudan in $2007^{(2)}$.

RVF has economic effects as it then transmits animals to humans, causing fever followed by complications in the eyes. Infection with RVF virus can lead to elevated mortality rates in newborn livestock and adult abortions ${ }^{(3)}$.

A few commercially available antiviral drugs can cause serious and significant adverse effects, particularly for patients receiving lifelong therapy for illnesses such as HIV. In addition, viruses have the ability to trick and infect host cells rapidly. All of these facts together have led to the prospecting of new antiviral drugs, particularly from natural products, as they make up more than $25 \%$ of the new drug prototypes approved in recent decades ${ }^{(4)}$.

Among natural product sources, animal venom has disclosed a huge potential for drug discovery ${ }^{(5,6,7)}$, and despite the damaging action mechanism of animal venom, most of them have potential medicinal characteristics to cure illnesses. So, the present work aimed to evaluate the antiviral / virucidal activity of Naja nubiae (Elapidae) venom against RVFV and HSV1 as an economy impact virus infection on the human 
and animal level.

\section{AIM OF THE WORK}

The aim of the current study was to evaluate the cytotoxicity of the snake venom and in vitro evaluate the Antiviral / virucidal activity of Naja nubia (Elapidae) venom against Rift Valley Fever (RVFv) and Herpes simplex virus type -1 (HSV-1) using cell culture.

\section{MATERIAL AND METHODS}

Vero cells (CCL-81) were kindly provided by the Cell Culture Department, Virology Sector, VACSERA, Giza, Egypt. The cell line was supplied at passage no. 147. Fetal calf serum, the $0.25 \%$ trypsin solution, and growth culture medium (199) supplemented with HEPES buffer and $200 \mathrm{mM}$ L-glutamine was supplied by Sigma Chemical Co. (St Louis, MO, USA).

\section{Determination of venom toxicity}

Cytotoxicity was conducted according to ${ }^{(8)}$, where growth medium was decanted from Vero cells precultured 96 micro titer plates. Venom was applied as starting concentration of $10 \mathrm{mg} / \mathrm{ml}$ in a series of 2 fold serially diluted pattern in serum free 199-E medium as $0.1 \mathrm{ml}$ of each dilution / well. Negative non-treated cell control was considered. Plates were incubated at $37^{\circ} \mathrm{C}$ (Jouan- France) and examined frequently for up to 3 days. Cells were checked for any toxic as partial or complete loss of monolayer, shrinkage, rounding, or cell granulation. The IC50 values were determined using Master Plex 2010 Software.

\section{Cell Viability (MTT Assay)}

Vero cells were propagated in $75 \mathrm{~cm}^{2}$ cell culture as previously mentioned according to ${ }^{(9)}$, where confluent sheet were detached using $0.25 \%$ (w/v) trypsin solution and $0.05 \%(\mathrm{v} / \mathrm{v})$ ethylene diaminetetra acetic acid (GIBCO- USA) for $5 \mathrm{~min}$. Cells were plated at a concentration of $2 \times 105 \mathrm{cell} / \mathrm{ml}$ in 96 -well cell culture plates and incubated at $37^{\circ} \mathrm{C}$ for 24 hours to achieve confluency.

The growth medium was decanted and fresh medium containing 2 fold serially diluted venom dispensed to cells (4 wells). 24 hrs. later dead cells were washed out using phosphate buffered- saline (PBS) and $50 \mu \mathrm{l}$ of MTT stock $(0.5 \mathrm{mg} / \mathrm{ml})$ were added to each well. After 4 hours incubation period, the supernatants were discarded and the formazan precipitates were solubilized by addition of $50 \mu \mathrm{l}$ per well of dimethyl sulfoxide (DMSO).

Plates were incubated in the dark for $30 \mathrm{~min}$ at $37^{\circ} \mathrm{C}$ and absorbance was determined at a wavelength of 570 nm using micro plate reader (ELX -800, Biotek- USA). The cell viability a percentage was calculated using the following formula:

Viability $\%=$ Mean OD of test dilution X 100 Mean OD of control

\section{Virus Models}

Rift Valley Fever strain (RVFV) pan tropic Menya Strain (Menya/Sheep/258) and Herpes simples type -1 (HSV - 1) were kindly provided by Dr. Aly Fahmy Mohamed Head of R \& D Sector, VACSERA, Egypt. The strain had a titer of $7.5 \log (10)$ and $36 \log (10) / \mathrm{ml}$

\section{Virus models titration}

The RVF and HSV-1 viruses were titrated in Vero cells according to the procedure described by ${ }^{(\mathbf{1 0}, 11,12)}$, and the median infective dose was calculated as previously described. Using the following equation:

Index $=(\mathbf{A}-50 \%) /(A-B) X$ Log dilution $\backslash{ }^{(10)}$

where $\mathrm{A}$ is the percentage of death at the dilution immediately above $50 \%$ and $\mathrm{B}$ is the percentage of death at the dilution immediately below 50\%. Then, the index was applied to the dilution that produced the percentage of death immediately above 50 percent.

\section{Antiviral Activity}

The antiviral potential of snake venom was monitored using (indirect way), where pre-cultured Vero cells were treated with the safe concentrations of snake venom for $24 \mathrm{hrs}$. Treatment medium was decanted and test RVFV and HSV-1 were prepared according to ${ }^{(13)}$ where viruses were 10 fold serially diluted. Virus dilutions were dispensed to the treated and non-treated cells. Virus infectivity titer was evaluated according to (14) and the antiviral activity was determined by subtracting the virus infectivity titer of treated cells from that untreated Virucidal activity

Test viruses were incubated with the safe concentration of test venom and $1 \mathrm{ml}$ samples were collected at $1 \mathrm{hr}$. interval. Collected samples were freeze till use. Defrost samples were 10 fold diluted s previous and titrated into precultured Vero cells the end point of each sample collected was recorded and infectivity titer was plotted against time to determine the depletion time of each virus ${ }^{(15)}$.

\section{Statistical analysis}

Results were expressed as means \pm SE. Statistical significance was calculated using one-way analysis of variance (ANOVA) followed byStudents Newman-Keulsposthoc tests for multiple comparisons. All the statistical analysis was carried out with the use of SPSS 17 software.

\section{RESULTS \\ Cytotoxic effect of test venom:}

The cytotoxic effect of test venom was assessed by recording the various morphological changes of cells. The viability $\%$ of treated cells was concentration dependent, it was found that Vero cells were rounded, detached from the surface and many cells showed 
irregular cell membrane and membrane blebbing in the same time the related IC50 value $9.3 \mu \mathrm{g} / \mathrm{ml}$ Figure (1).

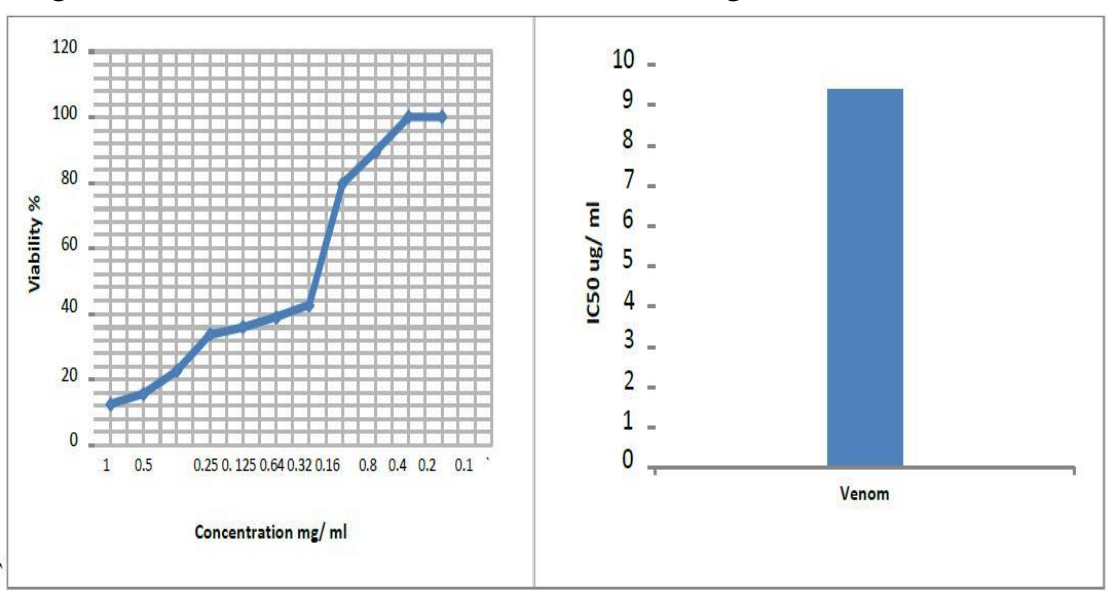

Figure (1): Evaluation of cytotoxicity and IC50 concentration against Vero cells

\section{Antiviral activity}

Regarding the antiviral activity of Naja nubaei venom showed a mild antiviral activity recording $0.72 \log _{10} / \mathrm{ml}$ $(9.2 \%)$. In the mean time antiviral activity of test venom showed a less antiviral potential against herpes simplex virus type 1 (HSV-1), as infectivity titer of HSV-1 showed a mild loss of viral infectivity as its titer was reduced in the order of $0.33 \log (10)$ recording depletion rate of $5.21 \%$ compared with the infectivity titer of untreated virus (Fig. 2)

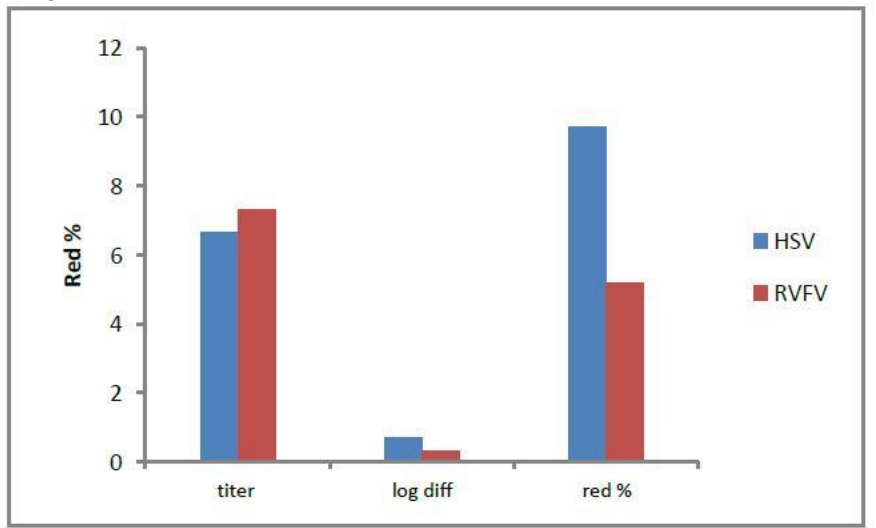

\section{Figure (2):}

Data recorded inactivation kinetics of RVFV using Snake venom showed that inactivation was time dependent, and the virus could not be detected within $12 \mathrm{hrs}$ post treatment and the depletion rate was $0.82 \mathrm{log}(10) / \mathrm{hr}(11.1 \%)$. In the mean times inactivation of HSV-1 virus showed an insignificant $(\mathrm{P}>0.05)$ depletion rate than in case of RVFV where the depletion rate was $0.73 \log (10)(11 \%)$ (Fig.3)

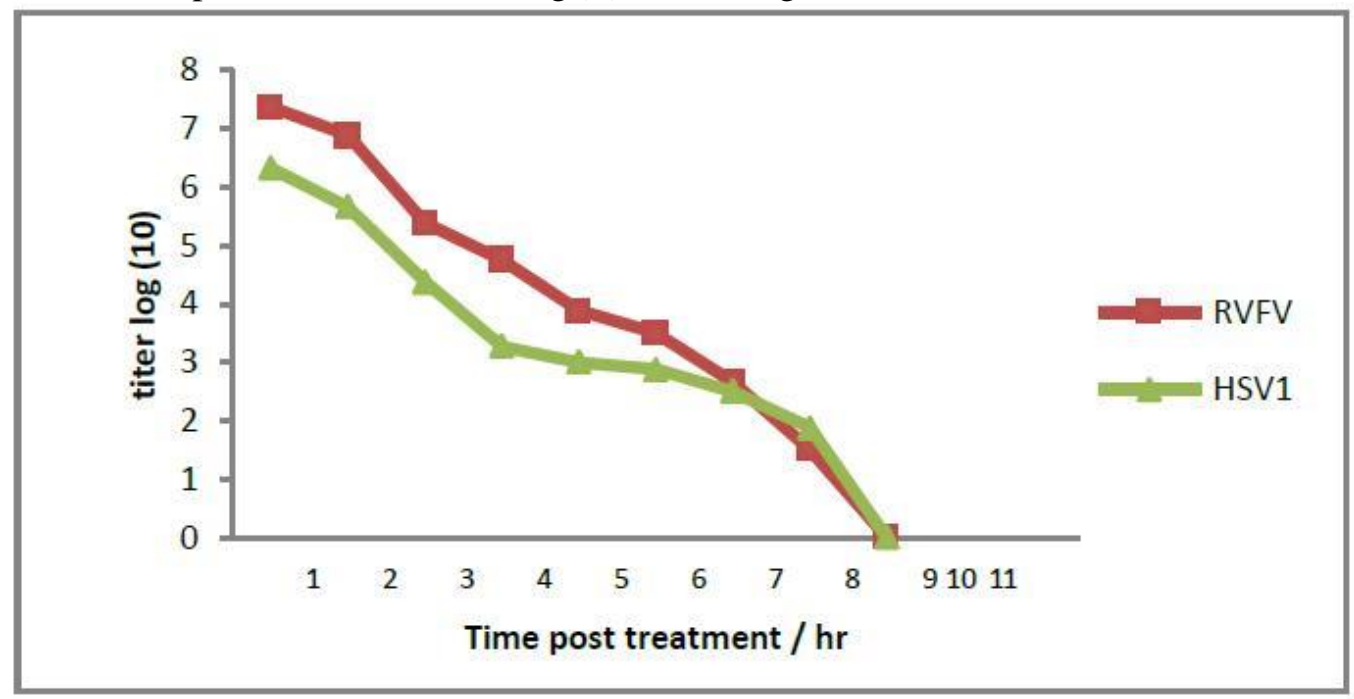

Figure (3): Evaluation of inactivation kinetics of RVFv and HSV-1 relative to time post treatment with snake venom 


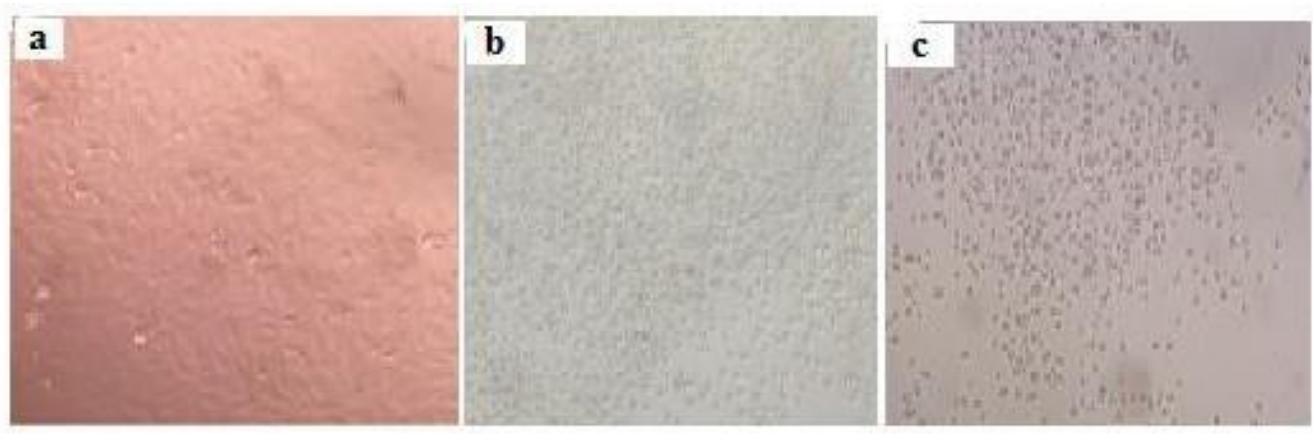

Figure (4): Evaluation O cytological alterative of vero cvells post treatment with test viruses a: cont, b: RVFv c: HSV-1

\section{DISCUSSION}

Rift Valley Fever is regarded as one of the most significant zoonotic viral diseases in Africa, affecting both animals and humans ${ }^{(\mathbf{1 6})}$. Mosquito bites transmit rift valley fever virus (RVFV) to humans. Symptoms of RVFV include acute fever and sometimes hemorrhagic retinal or hepatic problems. The fever's incubation period generally lasts 1 week. Generally, patients with this infection can recover readily, but complications can occur in less than five percent of patients. These complications include encephalitis, retinopathy or intravascular coagulation that leads to hemorrhage or death ${ }^{(17)}$.

Also, infection with oral herpes is mostly asymptomatic, the frequency of recurrence differs from individual to individual. Genital herpes induced by HSV-1 may have mild, unrecognized symptoms. When symptoms happen, 1 or more genital or anal blisters or ulcers characterize the genital herpes. Symptoms may recur after an original genital herpes episode, but genital herpes induced by HSV-1 often do not recur. The toxicity of venomous animal venoms is hazardous and it is necessary to optimize their implementation. Vero cells were shown to be clearly toxic in vitro application of venom and concentration dependent on toxicity. Our recorded information was consistent with Ayman et al. ${ }^{(8)}$ despite its use of scorpion venom on prostate cancer cells (PC3), they ascribed toxicity to the impact of scorpion venom owing to enzyme activity. There was also no explanation for high toxicity after PPD was added as $25 / 50 \mu \mathrm{g}$. The enhanced biochemical $\mathrm{H} 2 \mathrm{O} 2$ may also increase cell toxicity. Virucidal potential of venom can be attributed to excess peptide that may interfere with virus attachment, replication, and enzymatic activity that was consistent with da Mata $\boldsymbol{e t}$ al. (1) recoding that some peptides exhibit direct virucidal activity; others may interfere with virus particle attachment to the surface of the cell membrane or interfere with virus replication. Due to the restricted effectiveness of frequently used drugs and the emerging virus resistance. It has also been noted that Alyan et al. (18) antiviral peptides can have growth potential as putative therapeutic agents. The collateral impacts and toxicity of synthetic antiviral drugs have caused an extended search for natural compounds showing antiviral activity in relation to their decreased market accessibility. Any compound used as an antiviral should therefore conform to the pathways of the virus during the cellular infectious cycle.

Initially, any RNA or DNA virus, whether or not enveloped, expresses glycoproteins that are accountable for interacting with surface molecules, receptors, generally glycosylated proteins, incorporated into the host cell membrane. At this stage, any prospective antiviral candidate must compete with the cell receptor by inhibiting the virus ' attachment to the cell membrane and thus aborting the viral infection ${ }^{(\mathbf{1 9})}$.

Meanwhile, in agreement with da Mata et al. ${ }^{(1)}$ despite their use of scorpion venom, the LAAO enzyme is extremely specific to L-amino acids, and usually the finest substrates are hydrophobic amino acids. LAAO is a flavoprotein consisting of two identical subunits with approximately $60 \mathrm{kDa}$ of molecular weight each. The purified enzymes are 3-4 percent carbohydrate glycoproteins. The deglycosylation of the enzyme did not change its enzymatic activity, but its pharmacological activities appeared to change ${ }^{(20)}$.

Snake venom is perhaps the enzyme's wealthiest source. Snake venom LAAOs are usually very effective and are commonly used because of their chemo and stereospecificity to prepare $\alpha$-keto acids ${ }^{(21-22)}$. Useful therapeutic agents for certain microbial diseases are the $\alpha$-Keto acids of essential amino acids.

At the same time Mullera et al. ${ }^{(23)}$ it was revealed that dengue and yellow fever viruses are among the world's most significant arboviruses and it has been reported that Crotalus durissus terrificus snake venom phospholipases-A has elevated inhibitory capacity in Vero E6 cells against yellow fever and dengue viruses. The South American snake also provides venom with several molecules that are biologically active. Snake venom LAAO has once again become an interesting object for biomedical research due to its antimicrobial, anti-HIV, anticoagulant, platelet aggregation-inducing and inhibiting, apoptotic-inducing as well as anticancer activities.

LAAOs have been reported to have mildly deadly toxicity and virucidal activity, and latest trials have 
shown that LAAOs are multifunctional enzymes with edema-inducing, platelet-inducing or -inhibiting, apoptosis-inducing impacts, as well as anti-bacterial and anti-HIV-inducing impacts. During the oxidation process, these impacts were mainly mediated by the released $\mathrm{H} 2 \mathrm{O} 2$, but direct interactions between LAAO and the target cells could play a significant part. Snake venom LAAO is acknowledged by promising biomedical apps as a multifunctional protein ${ }^{(24)}$.

At the same time Shebl et al. ${ }^{(25)}$ it was revealed that LAAO can be used as a virucidal agent compared to presently recognized inactivating agents, namely formlin and BPL, and that LAAO not only showed a faster inactivating activity than BPL, but also considerably enhanced cellular and humoral immunity compared to animals immunized with BPL and Formalin-prepared vaccines. They also stated that LAAO has low antiviral activity and a very good virucidal activity against VSV and HSV-II, since the viruses could be fully inactivated within 6 hours of $37^{\circ}$ C therapy. In addition, BPL was used in the manufacturing of human vaccines and showed enhanced antigenicity in the RVFV vaccine and, in turn, enhanced vaccine potential despite the cost and dangerous impacts of exposure to BPL ${ }^{(26)}$.

Finally it was revealed that a large amount of compounds were recognized as inhibitors of multiple viral infections and progression of disease, making it urgent to find more efficient antimicrobial agents. In addition, very few viral medicines are accessible, and not all are effective, in proportion to the wide variety of illnesses induced by bacteria. New antiviral substances extracted from natural products, including those extracted from venomous animals, were therefore prospected. Venoms are complicated mixtures of hundreds of molecules, mostly peptides, presenting a wide range of biological activities and evolving to target the biochemical machinery of various pathogens or host cellular structures. In addition, non-venomous compounds, such as some body fluids of invertebrate organisms, exhibit antiviral activity.

\section{CONCLUSION AND RECOMMENDATIONS}

It could be concluded that Naja Nubiae venom is a potentially virucidal agent than antiviral one with persistent inactivation potential.

Recommended to be applicated on a wide range of DNA and RNA viruses, in the meantime it can be nanocapsulated for sustained release effect for safe application.

\section{REFERENCES}

1. da Mata ÉC, Mourão CB et al. (2017): Antiviral activity of animal venom peptides and related compounds. J Venom Anim Toxins Incl Trop Dis., 6:23-33.

2. Paweska JT (2008): Epidemiology of RVF: Potential Risks for introduction into Europe. http://www.scielo.br/scielo.php?
script=sci_arttext\&pid=S1516-89132016000100345

3. LaBeaud AD, Muchiri EM, Ndzovu M et al. (2008): Interepidemic Rift Valley fever virus seropositivity, northeastern Kenya. Emerg Infect Dis., 14(8):1240-6.

4. Martinez JP, Sasse F, Brönstrup M et al. (2015): Antiviral drug discovery: broad-spectrum drugs from nature. Nat Prod Rep., 32(1):29-48.

5. Vigerelli H, Sciani JM, Jared C et al. (2014): Bufotenine is Vigerelli able to block rabies virus infection in BHK-21 cells. J Venom Anim Toxins incl Trop Dis., 20(1):45-49.

6. Cunha-Neto RS, Vigerelli H, Jared C et al. (2015): Synergic effects between ocellatin- F1 and bufotenine on the inhibition of BHK-21 cellular infection by the rabies virus. J Venom Anim Toxins incl Trop Dis., 21:50-56.

7. Rivero JVR, de Castro FOF, Stival AS et al. (2011): Mechanisms of virus resistance and antiviral activity of snake venoms. J Venom Anim Toxins incl Trop Dis., 17(4):387-93.

8. Ayman M, Mohamed AF, Bakkar A et al. (2017): The Bacillus Calmette-Guérin Derived Purified Protein (PPD) Potentiates In-Vitro Anti-cancer Activity of Cerastes cerastes Snake Venom in Colon and Prostate Cancer Cells. http://inventi.in/journal/article/ impact/ 8/21276/molecular-pharmacology/pi

9. Bussereau F, Benejean J, Saghi N (1982): Isolation and study of temperature-sensitive mutants of rabies virus. Gen Virol., 60 (1):153-8.

10. Ali H, Hashem AG, EI Tayeb O et al. (2010): Evaluation of inactivation efficacy of Sabin Polio virus using different inactivating agents and its immunogenicity post nano and micro encapsulation. International Journal of Microbiological Research, 1: 114-122.

11. Kolodziej M, Joniec J, Bartoszcze M et al. (2011): Peptides - a new strategy for combating viral infections. Przegl Epidemiol., 65(3):477-82.

12. Reed LT, Muench HA (1938): simple method of calculating fty percent end point. Am J Hyg., 27: 493-498

13. Fenard D, Lambeau G, Valentin E et al. (1999): Secreted phospholipases A(2), a new class of HIV inhibitors that block virus entry into host cells. J Clin Invest., 104(5):611-8.

14. Fernandez S, Hodgson W, Chaisakul J et al. (2014): Invitro toxic effects of puff adder (Bitis arietans) venom and their neutralization by antivenom. Toxins, 6(5):15861597.

15. Al-Olayan EM, Mohame AF, El-Khadraqy MF et al. (2016): An Alternative Inactivant for Rift Valley Fever Virus using Cobra Venom-derived L-Amino Oxidase, which is Related to its Immune Potential. http://www.scielo.br/scielo.php?pid=S151689132016000100345 \&script=sci_abstract

16. Nina L, Jonas N, Ake L et al. (2009): Characterisation of immune responses and protective efficacy in mice after immunisation with Rift Valley Fever virus cDNA constructs. JVI., 6:6-9.

17. Balkhy HH, Memish ZA (2003): Rift Valley fever: an uninvited zoonosis in the Arabian peninsula. Int $\mathbf{J}$ Antimicrob Agents, 21:153-7.

18. Alyan MS, Shalaby MA, El-Sanousi AA et al. (2014): Antiviral and Anticancer Potentials of Snake and Scorpion Venom Derivatives. Inventi Rapid: Mol Pharma, 2:15-22. 
19. Torres TS, Cardoso SW, Velasque LS et al. (2014): Incidence rate of modifying or discontinuing first combined antiretroviral therapy regimen due to toxicity during the first year of treatment stratified by age. Braz $\mathbf{J}$ Infec Dis., 18(1):34-41.

20. Iwanaga S, Suzuki TL (1979): Amino acid oxidase. In: Lee CY ed. Handbook of experimental pharmacology. Berlin: Springer.

21. Szwajcer E, Brodelius P, Mosbach K (1982): Production of $\alpha$-keto acids. Part 2: Immobilized whole cells of Providenciasp. PCM 1298 containing L-amino acid oxidase. Enzyme Microb Technol., 4: 409-413

22. Findrik Z, Geueke B, Hummel W et al. (2006): Modeling of L-DOPA enzymatic oxidation catalyzed by L-amino acid oxidase from Crotalusadamanteus and
Rhodococcusopacus. Biochem Eng J., 27: 275-286.

23. Mullera VD, Russoa RR, Oliveira AC et al. (2012): Crotoxin and phospholipases A2 from Crotalus durissus terrificus showed antiviral activity against dengue and yellow fever viruses. Toxicon, 59(4): 507-51.

24. Du XY, Clemetson KJ (2002): Snake venom L-amino acid oxidase. Toxicon, 40: 659-665.

25. Shebl RI, Mohamed AF, Ali AE et al. (2012): Antimicrobial Profile of Selected Snake Venoms and Their Associated Enzymatic Activities. Br Microbiol Res J., 2(4): 251-263.

26. Zedan, MA, Mohamed FA, Tantawy HM et al. (2003): Comparative Evaluation of different enhancers to liquid Rabies vaccine at different thermal conditions. Egypt $\mathbf{J}$ Zool., 40:443-453. 